\title{
Fundamentals
}

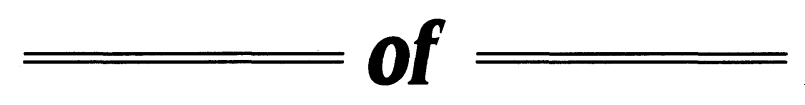

Engineering Elasticity 
This page is intentionally left blank 


\title{
Fundamentals
}

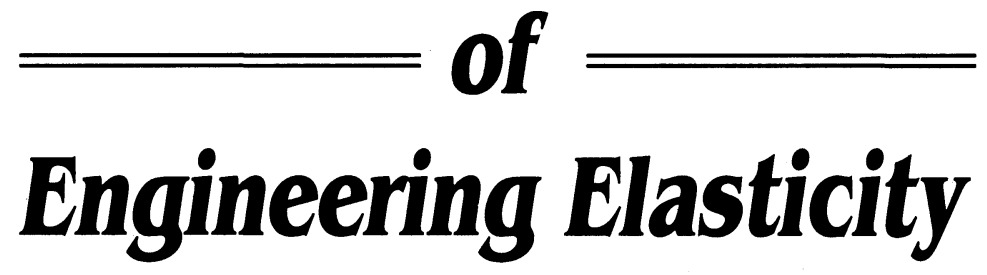

Second Edition

\author{
S. F. BORG \\ Professor Emeritus of Civil Engineering \\ Stevens Institute of Technology \\ Hoboken, NJ 07030, USA
}


Published by

World Scientific Publishing Co. Pte. Ltd.

P O Box 128, Farrer Road, Singapore 9128

USA office: 687 Hartwell Street, Teaneck, NJ 07666

UK office: 73 Lynton Mead, Totteridge, London N20 8DH

Library of Congress Cataloging-in-Publication data is available.

Printed in 1962 by Litton Educational Pub., Inc.

\section{FUNDAMENTALS OF ENGINEERING ELASTICITY}

Copyright $\odot 1990$ by World Scientific Publishing Co. Pte. Ltd.

All rights reserved. This book, or parts thereof, may not be reproduced in any form or by any means, electronic or mechanical, including photocopying, recording or any information storage and retrieval system now known or to be invented, without written permission from the Publisher.

ISBN 981-02-0164-8

981-02-0165-6 pbk

Printed in Singapore by JBW Printers \& Binders Pte. Ltd. 


\section{IN MEMORY OF AUDREY}

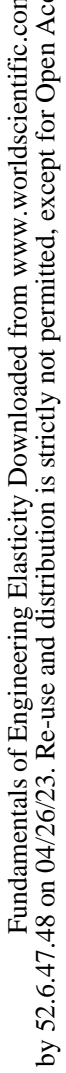


This page is intentionally left blank 


\section{PREFACE TO THE FIRST EDITION}

This book is intended for sophomore and junior students in engineering curricula.

It may be trite to repeat that we are living in an era of "exploding technology," but for engineers this statement does perhaps bear repetition. In any event, it is this fact which has led the author to write this textbook. It is his conviction that the properly educated engineer and engineering scientist of the present and future must have a grasp of the fundamentals of engineering.

If the modern engineering curriculum is to include all of the groundwork knowledge in the many different fields that the well-prepared engineering student must know, then it will be impossible to cover, in the four-year engineering curriculum, the subject material which in the past was included in structural engineering. This broad field included strength of materials (or mechanics of materials), elementary structural analysis, and elementary structural design.

How then are we to prepare the student for truly professional engineering practice in the present and future?

It would seem that there is only one method that will fit within the framework of a four-year undergraduate curriculum, and this is to present all subjects from their truly fundamental points of view. We must go back to the origins of all fields, re-exploring the assumptions, hypotheses and approximations that ultimately led to the development of the engineering forms of the various subjects.

In the subject now called "strength of materials," going back to the origins means taking as our starting point the subject matter of the mathematical theory of elasticity. Otherwise stated, the presentation of material in this text is based on the assumption that the fountainhead, or essential source, of all knowledge of structural theory and practice is the mathematical theory of elasticity.

The mathematical theory of elasticity may be called the parent, and the engineering elasticity (or strength of materials) the offspring, even though the latter developed at an earlier time than the former, because the mathematical and scientific justification of the theories developed in the strength of materials is only to be found in the body and extensions of the mathematical theory of elasticity. The engineering elasticity is essentially an approximation or simplification of the more exact theory, so that the practicing engineer could utilize the predictions and results of mathematical elasticity. Textbooks on strength of materials have presented the engineering form of the mathematical theory of elasticity, but rarely, if ever, has the relationship between parent and offspring been made clear. Understanding the relationship would seem to be essential if the student is to have 
a good understanding of the coverage presented. To present the subject in such a manner and with such goals is what the present textbook attempts to do for the student

Because this book is written for the beginning student of structural engineering, we start with an explanatory chapter in which the basic philosophy behind the writing of the book is outlined. The purpose of the book is stated clearly and, as additional background, a brief historical summary of the field is presented. This will further help to explain to the student the purpose and intent of the text.

Tensor, the family name of the quantities of mathematical physics and, hence, of engineering, is a concept all modern engineers should understand and be familiar with. The tensor is introduced most naturally in this book because straightforward matrix-tensor statements are especially adaptable to discussions of engineering elasticity. For this reason, matrix-tensor arguments are utilized wherever possible. A basic, elementary treatment of matrix-tensor theory, suitable for our purposes, is given in Chapter 2. In this chapter also the elements of finite difference calculus are dealt with, because this also is a valuable tool that engineers should be familiar with and because elementary finite difference methods fit naturally into the framework of the coverage of the book.

The equations of the linearized theory of elasticity are presented next, and then it is shown how the ordinary, simplified structures of everyday engineering usage are analyzed using outgrowths and simplified forms of the basic, more exact theories. It is clearly shown just what approximations and assumptions are introduced in the basic theory of the engineering analysis - and it is shown why they are introduced.

In the remaining chapters the analysis of the key structural units (the bar, beam, etc.) is presented, first in the more exact linearized theory of elasticity solutions, and then in the approximate engineering solutions.

Extensions of the engineering analysis (the shear-moment curve construction, conjugate beam method, etc.) are introduced, where applicable, to indicate the directions in which this field has advanced.

Many problems dealing with the text material have been included, because an undergraduate engineering or science student can truly master his subject only when he can solve quantitative problems in connection with it.

In summary, then, the book has been written because the author believes the student in engineering must have a training and background in the field covered by the text. It is also the author's sincere hope that practicing engineers in the fields of applied mechanics and structural engineering will find the book worth while. 


\section{PREFACE TO THE SECOND EDITION}

The second edition follows the format of the first one. Several typographical errors have been corrected and several new topics or extensions of the original material have been included in an Appendix following Chapter 13 at the end of the book.

Overall however, the two fundamental premises have been adhered to, namely:

1. In order to attain a real understanding of the subject which we call "strength of materials" or "mechanics of materials" one must go back to the beginnings of these fields - the linearized mathematical theory of elasticity. Hence the title of the book stressing the words engineering elasticity.

2. The field of engineering elasticity is a good one to utilize in introducing to the undergraduate engineering student the important and useful topic of tensors. And for the engineer the matrix representation of the tensor is the easiest to visualize and to understand. Hence the use of the matrixtensor notation.

The author wishes to express sincere thanks to his publishers, World Scientific Publishing Co., for reprinting the text and for their continual help and encouragement in seeing this task through to completion. 
This page is intentionally left blank 


\section{CONTENTS}

CHAPTER

PAGE

PREFACE TO THE FIRST EDITION vii

PREFACE TO THE SECOND EDITION ix

1. INTRODUCTION AND HISTORICAL BACKGROUND 1

1-1 Introduction 1

1-2 Brief Historical Survey 4

2. MATHEMATICAL PRELIMINARIES: THE ELEMENTS OF MATRIX-TENSOR THEORY AND OF THE FINITE DIFFERENCE METHOD

2-1 Introduction 6

2-2 Matrix Algebra $\quad 7$

2-3 Scalar, Vector and Tensor Analysis 12

2-4 The Scalar 12

2-5 The Vector 13

2-6 The Tensor 16

2-7 Brief Remarks on the Tensor Notations 20

2-8 Finite Difference Method - Introduction 20

2-9 Outline of the Finite Difference Method 21

2-10 Summary 24

3. THE TENSORS OF ELASTICITY - THE INERTIA, STRAIN, AND STRESS TENSORS 28

3-1 Introduction 28

3-2 The Inertia Tensor $\quad 28$

3-3 The Strain Tensor 36

3-4 The Complete Non-Linear Strain Tensor 41

3-5 The Stress Tensor 41

3-6 Summary 44

4. THE CONNECTION BETWEEN THE LINEARIZED MATHEMATICAL THEORY OF ELASTICITY AND ENGINEERING ELASTICITY 47

$\begin{array}{lll}4-1 & \text { Introduction } & 47\end{array}$ 
4-2 The Equations of Equilibrium in the

Linearized Theory of Elasticity

4-3 The Boundary Conditions in the

Linearized Theory of Elasticity

4-4 The Strain Compatibility Conditions in

the Linearized Theory of Elasticity

4-5 Hooke's Law in the Linearized Theory of Elasticity

4-6 The Two-Dimensional Form of the Equations of the Linearized Theory of Elasticity

4-7 The Engineering Form of the Equations of the Theory of Elasticity

4-8 The St. Venant Principle

4-9 Summary

5. THE SIMPLE TENSION-COMPRESSION STRUCTURE - THE TRUSS

5-1 Introduction $\quad 69$

5-2 The Tension-Compression Bar in Elasticity 69

5-3 The Truss in the Theory of Elasticity 73

5-4 The Engineering Solution of the Truss 74

5-5 The Deformation of the Engineering Truss 79

5-6 Summary $\quad 81$

6. THE SIMPLEST SHEAR-TENSION-COMPRESSION STRUCTURE - THE BEAM

6-1 Introduction

6-2 The Pure Moment Acting on a Bar the Theory of Elasticity Solution

6-3 The Engineering Elasticity Solution For the Beam The Bernoulli-Euler Solution

6-4 The Shear, Moment, Slope, Deflection Relations

6-5 The Loads on an Engineering Beam

6-6 The Shear Stress in the Engineering Beam 97

6-7 The Shear and Moment Curves 100

6-8 The Approximation Involved in the

Bernoulli-Euler Solution for the Beam 102

6-9 Summary

7. SHEAR AND MOMENT DIAGRAMS 108

$\begin{array}{lll}7-1 & \text { Introduction } & 108\end{array}$

7-2 The Basic Shear and Moment Curves 108

7-3 The Shear Curve for Several Loads on the Beam 112 
CHAPTER

7-4 The Moment Diagram by Parts

7-5 The Combined Moment Curve

7-6 Summary

8. THE BENDING STRESS AND

SHEAR DESIGN OF BEAMS

8-1 Introduction 127

8-2 Steel and Timber Beam Design 127

8-3 Structural Analysis - Investigation and Design 130

8-4 Steel Beams - Three Examples 130

8-5 Timber Beams - Investigation and Design 138

8-6 Summary 144

9. DEFLECTION OF BEAMS 148

9-1 Introduction 148

9-2 The Double Integration Method 149

9-3 The Moment-Area Method 153

9-4 The Conjugate Beam Method 160

9-5 Special Support Conditions of the Conjugate-Beam Method 163

9-6 Deflections by the Finite Difference Method 167

9-7 A Finite-Difference Solution Using $E I_{3} \frac{d^{4} v}{d x^{4}}=w(x) \quad 171$

9-8 Summary 173

10. STATICALLY INDETERMINATE BEAMS 176

10-1 Introduction 176

10-2 Statically Determinate Beams 176

10-3 Statically Indeterminate Beams 178

10-4 Strain or Deformation Compatibility for Indeterminate Beams

180

10-5 Indeterminate Beam Solution by the Conjugate Beam Method

10-6 The Indeterminate Beam Solved by the Finite Difference Method

10-7 Summary

11. BENDING INSTABILITY -

THE DESIGN OF COLUMNS 193

11-1 Introduction 
11-2 The Euler Solution for a Hinged-Hinged Column

11-3 The Euler Solution for Other End Conditions

11-4 The Inconsistency in the Euler Solution

11-5 The Elastica - a Column With Large Deflections

11-6 Column Behaviour When Stresses Exceed the Proportional Limit

11-7 The Engineering Form of the Column Formulas 215

11-8 The Design and Investigation of Engineering Columns 217

11-9 Critical Buckling Loads Obtained by the Finite Difference Method

11-10 Summary

12. THE TORSION PROBLEM 228

12-1 Introduction 228

12-2 The Pure Shear Structure 228

12-3 The Classical St. Venant Torsion Solution 230

12-4 Two Exact Solutions to the Torsion Problem 236

12-5 Torsion Solutions For Other Cross-Sectional Shapes 241

12-6 The Square Cross Section Solved by the Finite Difference Method 242

12-7 Summary

13. ENGINEERING ELASTICITY ANALYSIS

OF SPECIAL STRUCTURES

13-1 Introduction

13-2 The Cable and the Membrane 249

13-3 The Cable

249

13-4 The Membrane

13-5 The Membrane Solution for the Cylindrical Container

13-6 The Membrane Solution for the Spherical Container

13-7 The Rigid Frame and Its Relation to the Continuous Beam

13-8 A Rigid Frame Solution Using the Conjugate Beam Method 
CONTENTS

$\begin{array}{ll}\text { REFERENCES } & 271\end{array}$

$\begin{array}{ll}\text { INDEX } & 273\end{array}$

$\begin{array}{lr}\text { APPENDIX } & 277\end{array}$

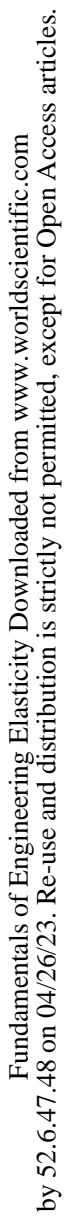

